\title{
Mindfulness for female outpatients with chronic primary headaches: an internet-based bibliotherapy
}

\author{
Vahid Tavallaei (1), Yaser Rezapour-Mirsaleh (2), Peyman Rezaiemaram (3), Seyed \\ Hassan Saadat (4) \\ (1) Counseling Department, Education \& Psychology Faculty, Ardakan University, Ardakan, \\ Iran; (2) Counseling Department, Education \& Psychology Faculty, Ardakan University, \\ Ardakan, Iran; (3) Psychology Department, Faculty of Humanities, Tarbiat Modares University, \\ Tehran, Iran; (4) Behavioral Science Research Center, Lifestyle Institute, Baqiyatallah \\ University of Medical Sciences, Tehran, Iran
}

This article is distributed under the terms of the Creative Commons Attribution Noncommercial License (CC BY-NC 4.0) which permits any noncommercial use, distribution, and reproduction in any medium, provided the original author(s) and source are credited.

\begin{abstract}
Our aim was to investigate effectiveness of mindfulness by bibliotherapy on disability, distress, perceived pain and mindfulness in women with tension headaches and migraines. Primary headaches have been of great interest to mental health researchers because of the high prevalence, as well as significant disability and distress in the affected people. Despite the promising results of in-person treatment and some limitations that such interventions may cause, patients may be encountered with problems when using health care services. The present study is a quasi-experimental randomized design with pre-test, post-test, and control group. The study population consisted of 1396 women with migraine headache referring to headache clinic of Baqiyatallah Hospital in Tehran. Of these, 30 patients (including tboh experimental and control group) were selected by objective sampling method and were randomly assigned to the two groups. The experimental group, in addition to medical treatment as usual, was treated for a period of 8 sessions by Mindfulness-based Stress Reduction Internet-based Bibliotherapy, but the control group used only the medical treatment. The sample had no attritions. Data were collected by the four scales of (DASS-21), Migraine Disability Assessment Test (MIDAS), McGill's Short Form Questionnaire (MPQ-SF), and Mindfulness Inventory (MAAS). We used covariance analysis to analyze the findings in the measured scales. MBSR-IBB treatment had no significant effect on pain sensory dimension ( $\mathrm{P}<0.44$ ), despite improvement of mindfulness $(\mathrm{P}<0.0001)$. In contrast, the greatest effect was on the level of disability $(\mathrm{P}<0.0001)$. We observed also a significant improvement in distress $(\mathrm{P}<0.0001)$. In conclusion, in spite of the presence of headaches, the mindfulness improved the quality of life and reduced the level of mental distress. In addition, using the Internet-based bibliotherapy method, these services can be used with easier access, lower cost, and more flexibility.
\end{abstract}

Key Words: Mindfulness-based stress reduction, Internet-based bibliotherapy, primary headache

Eur J Transl Myol 28 (2): 175-184, 2018

Primary headache is the most common pain syndrome. ${ }^{1}$ Tension-type headaches and migraines have been reported as the second and third common disorders, respectively. ${ }^{2}$ According to epidemiological studies, the number of people with primary headaches is on the rise, such that in 2015, the number of people with tension headache was 1 billion 506 million people and for migraine was 956 million around the world which is estimated to be by $15.3 \%$ more on average than $2005 .{ }^{3}$ In addition, in Iran, research shows that there is a high prevalence of primary headaches. Especially, the prevalence of migraine and tension headache in Tehran, the capital of Iran, is estimated to be 18.2 and $48.6,{ }^{4}$ respectively, which exceeds many other cities, including Shiraz (11.2 and 19.5 , respectively) and Zahedan (migraine $=7.14) .{ }^{5,6}$ Decreased performance and reduced quality of life are among the major implications of early 
Table 1. Outline of treatment package (weekly framework)

\begin{tabular}{|c|c|}
\hline Courses & Contents of Courses \\
\hline Introduction & $\begin{array}{l}\text { The process of holding the course and its duration, the benefits of the course as compared to other } \\
\text { courses, talking about stress and anxiety, mindfulness in simple language, consent form }\end{array}$ \\
\hline Week 1 & $\begin{array}{l}\text { Reasons for choosing the course, stress and anxiety and their role in life, list of stressors, raisins } \\
\text { eating practice, "Mindful Check-in" practice, planning and reviewing practices }\end{array}$ \\
\hline Week 2 & $\begin{array}{l}\text { Triangle of cognition, emotion and body senses, Stress reaction and stress response, mindful } \\
\text { breathing practice, mindfulness for everyday stress, planning and reviewing practices }\end{array}$ \\
\hline Week 3 & $\begin{array}{l}\text { Stages of mindfulness, bringing the stages of mindfulness into life, the effects of mindfulness on } \\
\text { headache, mental traps and negative self-talk, wandering mind, "mindful breathing" practice, } \\
\text { "mindful walking" practice, planning and reviewing practices }\end{array}$ \\
\hline Week 4 & $\begin{array}{l}\text { Benefits of mindfulness for body health, "body scan" practice, dealing with physical pain, } \\
\text { Identifying Emotions in the Body, barriers to awareness of emotions, planning and reviewing } \\
\text { practices }\end{array}$ \\
\hline Week 5 & $\begin{array}{l}\text { "mindful sitting" practice, regular patterns, being mindful of habits, mindful physical exercises } \\
\text { (1), planning and reviewing practices }\end{array}$ \\
\hline Week 6 & $\begin{array}{l}\text { Mindful self-inquiry, reconciliation with hard feelings, discovery of internal rules, mindful } \\
\text { physical exercises (2), planning and reviewing practices }\end{array}$ \\
\hline Week 7 & $\begin{array}{l}\text { "loving-kindness meditation" Practice, mindfulness in interpersonal relationships, six qualities of } \\
\text { mindful relationship, "mindful listening" practice, planning and reviewing practices }\end{array}$ \\
\hline Week 8 & $\begin{array}{l}\text { "Mindful eating" practice, "mindful exercising" practice, "mindful resting" practice, "mindful } \\
\text { communications" practice, communication barriers, reviewing the stressors list, planning and } \\
\text { reviewing practices, planning for the future and continuing, finish }\end{array}$ \\
\hline
\end{tabular}

headaches. ${ }^{1,7,8}$ Particularly migraines have been reported in people under age 50 as the third cause of disability. ${ }^{9}$ Although tension headaches have less disability than migraine headaches, ${ }^{10}$ because of longer periods of headaches in affected individuals, as well as higher incidence, these cause significant loss of performance. ${ }^{11,12}$ Primary headaches are complex and multidimensional. ${ }^{13-15}$ According to pathological studies, several factors are involved in the occurrence of tension and migraine headaches, including biological, ${ }^{16}$ psychological and social factors. ${ }^{17-21}$ In addition, gender differences create another effective factor that can affect people's headache. ${ }^{18,21}$ Several psychological variables are associated with primary headaches, including stress, ${ }^{18,19,22,23}$ anxiety and depression. ${ }^{24-26}$ cognitive structures, ${ }^{27-29}$ personality traits, ${ }^{30.31}$ coping styles. ${ }^{32}$ For this reason, researchers have investigated the effectiveness of various psychological therapies on people with headache. ${ }^{33,34}$ Considering the emphasis of research literature on the driving role of stress in tension headache and migraine, ${ }^{1,5,18,19}$ a significant number of these studies has been devoted to stress reduction methods, especially the first and second generations of behavioral and cognitive therapies. ${ }^{35-37}$. But despite scholarly support, there are criticisms on them. For example, many of these methods are focused on avoiding headache triggers. ${ }^{34}$ Though avoiding triggers may be effective in the short term, in the long run it increases the potential of triggers to cause headaches. ${ }^{34}$ Another group of studies have emphasized change in cognitive and emotional content of the headache. ${ }^{38}$ All together, the results indicate a small effect of these methods on the generation and disability level in patients with chronic pain. ${ }^{39-41}$ For this reason, the third generation of behavioral therapies focus on encounter and acceptance rather than controlling triggers and changing cognitive and emotional content. ${ }^{42,43}$ One of the acceptance-based treatments is the reduction of mindfulness-based stress reduction (MBSR). This treatment is a third-generation behavioral therapy and several groups have studied its effectiveness. ${ }^{44-46}$ The outcomes indicate that this method is effective in reducing perceived pain intensity, performance limitation, ${ }^{47,48}$ stress, ${ }^{46,49}$ duration of depression, high recurrence, worse quality of life and worsening of mental health in patients with chronic pain. ${ }^{46,50}$ In addition, research has shown the effecacy of MBSR, in patients with primary headaches, on improving quality of life, individual performance, and reducing stress, anxiety and depression. ${ }^{47,48,51}$ Despite the promising results of these interventions, they face some constraints, including lack of access of many people to mental health services, high cost, time-intensiveness, and cultural problems created in the referral for treatment. ${ }^{52-}$ 55 Therefore, in addition to effectiveness, it is important to consider availability, cost, and timeliness of treatment. ${ }^{55}$ Hence, in recent years, self-help methods (such as telephone counseling, internet-based psychotherapies, bibliotherapy) became popular. ${ }^{53}$ 
Table 2. Outline of treatment package (flow-chart)

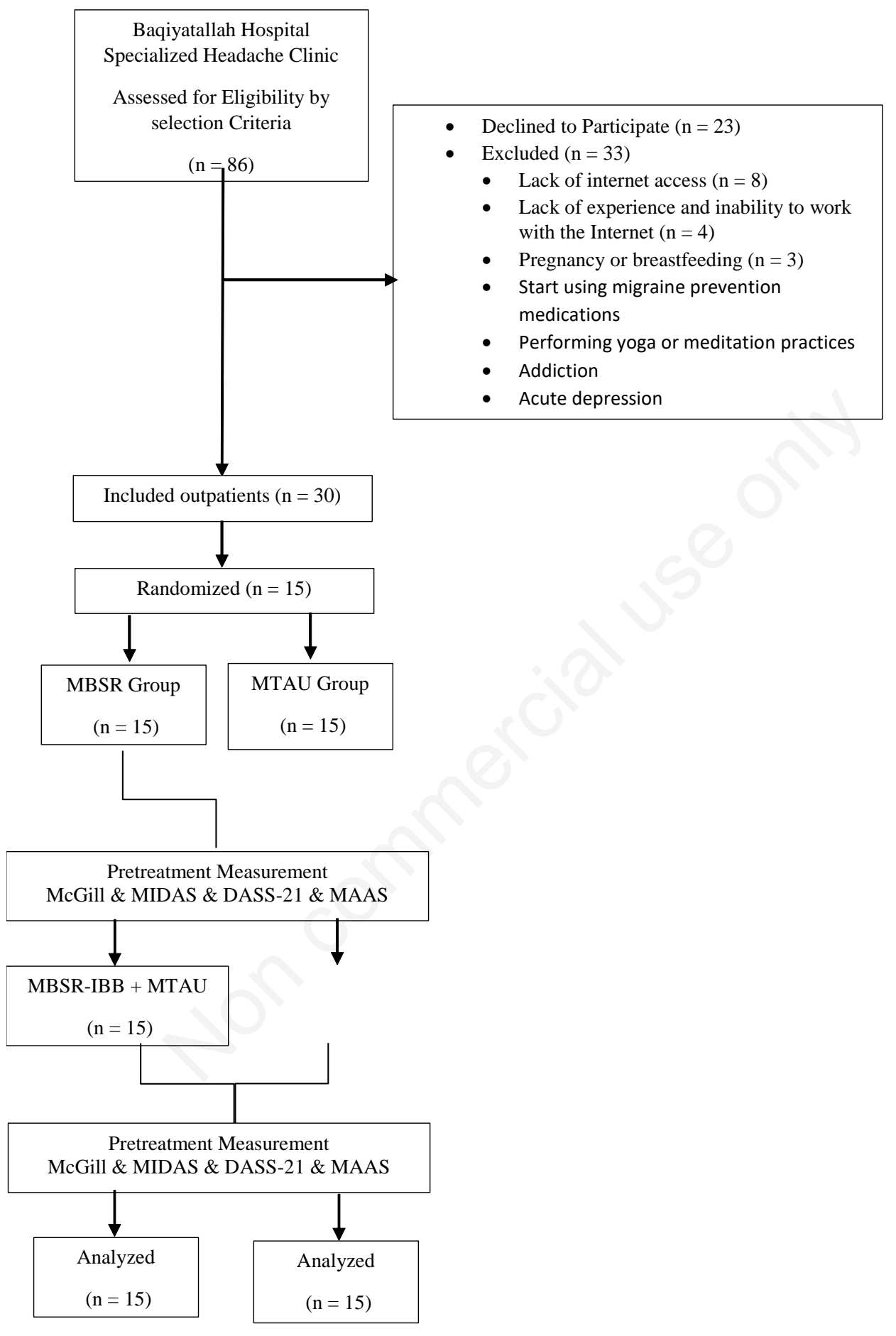

Bibliotherapy is one of these methods whose efficacy has been proven. ${ }^{56-58}$ Different researches have shown the effectiveness of bibliotherapy in solving different problems such as stress and anxiety, ${ }^{53-54}$ chronic pain, sleep problems, physical complaints, timeliness, depression, ${ }^{55}$ and aggression. ${ }^{61}$ Many studies have even shown that self-helped therapies have the same effects of in-person treatments. ${ }^{62}$ Therefore, the aim of this study was to investigate effectiveness of MBSR in Internetbased bibliotherapy on severity of pain, distress, disability, and mindfulness in women with tension and migraine headaches. 


\section{Materials and Methods}

The present study is a quasi-experimental randomized design with pre-test-post-test design with control group. In this study, two groups (test and control) were evaluated in two stages (pre-test and post-test). The statistical population of this study included all women who referred to the headache clinic of Baqiyatallah Hospital in Tehran. Of them, 1396, who, according to the clinical diagnosis of a physician in accordance with the criteria of the International Association of Headache, ${ }^{1}$ had been identified suffering with tension headache and migraine. In this research, the objective-based sampling was performed based on the inclusion and exclusion criteria. Inclusion criteria: 1. Diagnosis of tension headache and migraine by expert physician based on criteria of the International Association for Headache; 2. Age 18-50 years, 3. Least education degree of diploma, 4. Access to Internet and social network of Telegram. Exclusion Criteria: 1. Severe psychiatric disorders; 2. Addiction; 3. Regular meditation or yoga exercises; 5. Pregnancy and breastfeeding; 6. Starting a new medical treatment to prevent headaches within the next 45 days. Accordingly, 30 people were randomly assigned to the experimental and control groups using random numbers after being informed about the nature and objectives of the research, as well as taking an informed consent (each group included 15 people). For the control group, only the medical treatment as usual (MTAU) was performed. For the experimental group, in addition to the MTAU, the MBSR treatment was performed as bibliotherapy based on an 8-week treatment protocol. The protocol used in this study was designed using valid researches on mindfulness and third generation behavioral therapy and self-help bibliotherapy. ${ }^{42,63-69}$ After writing the original text, the book was given to two psychologists with experience in the field of mindfulness, to be examined in terms of the adaptation of the text to the underlying assumptions of the mindfulness. A summary of the MBSR educational-therapeutic package is presented in Tables 1 and 2. During these 8 weeks, the experimental group participants were followed up weekly in a specific day and time by the support therapist and were questioned about their weekly exercise, and their ambiguities were clarified (30 minutes per week). Two weeks after the therapeutic-research period, the subjects of both groups were called out. The instruments used in research in the MBSR group were recompleted in this face to face meeting and received at the same meeting. Also in the control group, after completing the relevant questionnaires in the post-test, subjects who wanted to receive psychological treatment were treated with MBSR.

\section{Results and Discussion}

Table 3 shows the demographic data of participants, including age, marital status, and educational level. Data were analyzed using multivariate analysis of covariance test at inferential level. For this purpose, before analysis, the assumptions of covariance analysis were investigated using Levine's test, and the results showed that the distribution of data was normal, and variances were uniform. The mean and standard deviation of the headache intensity, distress, disability and mindfulness of the patients in the experimental and control groups are

Table 3. Demographic data of clients in the two groups MTAU and MBSR

\begin{tabular}{|l|l|l|}
\hline Categorical Variable & $\begin{array}{l}\text { MTAU Group } \\
(\mathrm{n}=15)\end{array}$ & $\begin{array}{l}\text { MBSR Group } \\
(\mathrm{n}=15)\end{array}$ \\
\hline $\begin{array}{l}\text { Headache Diagnosis Frequency } \\
\text { Chronic Tension-type (\%) }\end{array}$ & $6(40)$ & $4(27)$ \\
Chronic Migraine (without aura) (\%) & $9(60)$ & $11(73)$ \\
\hline Marital status Frequency & $6(40)$ & $8(53.3)$ \\
Single (\%) & $9(60)$ & $7(46.6)$ \\
Married (\%) & $7(46.6)$ & $10(66.6)$ \\
\hline Employment & $8(53.3)$ & $5(33.3)$ \\
Employed (\%) & $34.87(9.12)$ & $32.47(9.11)$ \\
\hline Unemployed (\%) &
\end{tabular}


Table 4. Results of multivariate covariance analysis with mean and standard deviation for the experimental and control groups

\begin{tabular}{|c|c|c|c|c|c|c|}
\hline \multirow{2}{*}{$\begin{array}{c}\text { Variable } \\
\text { (Scoring Range) }\end{array}$} & \multirow{2}{*}{ Group } & \multirow{2}{*}{ Pre-treatment } & \multirow{2}{*}{ Post-treatment } & \multicolumn{2}{|c|}{ MANCOVA } & \multirow{2}{*}{$\begin{array}{c}\text { Effect } \\
\text { Size }\end{array}$} \\
\hline & & & & $\mathrm{F}$ & $\mathrm{P}$ & \\
\hline \multirow[t]{2}{*}{ Pain Intensity (0-45) } & \multirow{2}{*}{$\begin{array}{l}\text { MTAU } \\
\text { MBSR }\end{array}$} & $33.13(7.61)$ & $29.73(6.30)$ & \multirow{2}{*}{3.8} & \multirow{2}{*}{0.035} & \multirow{2}{*}{0.39} \\
\hline & & $32.93(6.67)$ & $24.03(11.21)$ & & & \\
\hline \multirow[t]{2}{*}{ Distress (0-42) } & MTAU & $31.67(11.36)$ & $20.6(7.43)$ & \multirow{2}{*}{18.21} & \multirow{2}{*}{$<0.0001$} & \multirow{2}{*}{0.59} \\
\hline & MBSR & $30.27(8.37)$ & $17.13(4.79)$ & & & \\
\hline \multirow[t]{2}{*}{ Disability (0-30) } & MTAU & $29.93(10.95)$ & $24.33(8.09)$ & \multirow{2}{*}{34.79} & \multirow{2}{*}{$<0.0001$} & \multirow{2}{*}{1.26} \\
\hline & MBSR & $33.67(12.40)$ & $11.60(5.32)$ & & & \\
\hline \multirow[t]{2}{*}{ Mindfulness (15-90) } & MTAU & $49.53(7.03)$ & $53.73(7.78)$ & \multirow{2}{*}{14.32} & \multirow{2}{*}{$<0.0001$} & \multirow{2}{*}{2.25} \\
\hline & MBSR & $52.40(6.42)$ & $70.67(5.56)$ & & & \\
\hline
\end{tabular}

presented in Table 4. The results of covariance analysis with the elimination of pre-test showed a significant difference between the mean scores of the experimental and control groups in pain intensity index $(\mathrm{P}<0.035)$, distress ( $\mathrm{P}<0.0001)$, disability $(\mathrm{P}<0.0001)$, and mindfulness ( $\mathrm{P}<0.0001)$ (Table 3 ). In addition, due to the special emphasis of the MBSR on the separation of the sensory dimension of pain from its emotional dimension, ${ }^{69}$ the sub-scales have been reported separately (sensory dimensional pain and emotional lateral pain). According to the results, it can be concluded that the results of covariance analysis show a significant difference between the scores of the experimental and control groups in the emotional dimension of pain ( $P$ $<0.0001)$, although there was no significant difference in sensory dimension $(\mathrm{P}<0.44)$.

This study was to investigate the effectiveness of mindfulness internet-based bibliotherapy on women with primary headaches (tension-type headache and migraine). According to the present study, pain intensity, distress, disability and mindfulness were all improved. As noted in the results, the overall pain intensity score improved. This finding is consistent with the findings of some studies on chronic pains, ${ }^{38,43,76-78}$ and headache, ${ }^{47}$ but not consistent with the results of some other studies in this area. ${ }^{48}$ Wells et al. investigated the effects of mindfulness on migraine patients, and the results of the pain intensity scale showed no reduction in the migraine headache intensity. ${ }^{48}$ In another study, acceptance and commitment therapy was performed for Iranian women with migraine and tension headaches, and the severity of perceived headache did not decrease significantly. ${ }^{42}$ Also, in a meta-analysis that was conducted on the effectiveness of MBSR in a variety of chronic pains (including primary headaches), the improvement in headache severity was lower than that of other pain types. ${ }^{59}$ Regarding the association of some psychological characteristics with headache intensity, ${ }^{1,18,19,29}$ it can be argued that psychological mechanisms related to perceived pain intensity in primary headaches are different from that of other chronic pain types. Because mindfulness techniques make fundamental changes in subject's lifestyle, ${ }^{79,80}$ it is anticipated that in the long run, the intensity of pain decreases in the sensory dimension. ${ }^{81}$ Future studies can examine this difference. On the other hand, there was no significant difference between the two groups in the sensory dimension, despite the significant difference between the two groups in terms of total pain intensity. In contrast, in the affective dimension, a significant improvement was observed in the MBSR group compared to the MTAU group. Also, improvement of distress in MBSR group are additional findings of the present study. According to Reiner et al., ${ }^{80}$ with increasing mindfulness, one gets detached from negative emotions and thoughts related to pain and acceptance and willingness toward pain are increased, following which, the intensity of the perceived pain decreases. In other words, by increasing mindfulness and acceptance, distress derived from experiential avoidance and refusal of dirty pain is decreased ${ }^{82,83}$ In this way, reducing the pain intensity score is due to reduced individual avoidance of pain and increased pain reception. This point indicates the importance of separation between the sensory and the affective dimensions, on which KabatZinn, the founder of the MBSR, emphasized. ${ }^{69}$ Therefore, it can be predicted that the reduction in pain intensity in 
previous studies was due to the lack of separation between these two dimensions. Future research can examine this hypothesis.

In addition, the performance of the MBSR group was significantly improved compared to the MTAU. These findings are consistent with the assumptions of acceptance and mindfulness treatments. In general, the main purpose is to change the functioning of personal experiences (that is, the negative effects of negative thoughts and unpleasant feelings on behavior), not direct change of personal experiences (for example, changing the content or the frequency of thoughts). ${ }^{43}$ In fact, the main focus of these treatments is on improving one's performance, despite some unpleasant experiences. $^{38,43,76,84}$ According to Reiner et al., with increasing mindfulness, despite of the existence of pain, efficient and self-regulated behaviors increase, thereby improving the performance and quality of life. ${ }^{80}$

One of the important features of this research is its selfhelp feature. Although in the in-person treatment, the therapeutic communication is itself an effective ingredient in the treatment process, ${ }^{85}$ in mindfulnessbased therapies, ${ }^{86-88}$ some constraints such as cultural problems, fear of referral to the therapist, $, 89,90$ transportation problems, and high cost of treatment make people with headache unwilling to go to a therapist or to continue treatment. Although no quantitative comparison was made, a roughly akin comparison between the results of this study and other studies conducted on the subject area of mindfulness for people with headache showed a relatively similar effectiveness of the evaluated variables. $^{42,48}$ Therefore, self-help treatments (such as bibliotherapy or treatment with educational packages or using the Internet), especially when people are not able to access in-person health care services for any reason, can be an appropriate and reliable treatment plan. Another important feature of this study is the lack of attrition of the subjects studied. Although it is anticipated that due to some proprietary features (including cost and time savings, nonexistence of transportation problems, and time flexibility of sessions), Internet-based and selfhelp interventions have fewer attritions, ${ }^{53-55,89}$ but the non-attrition of the subjects in the present paper cannot be attributed solely to these attributes. As Melville et al. have pointed out, ${ }^{94}$ in some Internet-based methods, some non-specific features are also effective in reducing the attrition of subjects: 1 . The average age of close to 33 years: The average age of the subjects in this study was 32.47 years; 2 . Female gender: In this study, all subjects were females; 3 . Unemployment in part-time work; 4. Experience with the Internet and online software tools: one of the inclusion criteria for the research. It is recommended that in future studies, while controlling non-specific variables, the effect of specific variables of self-help treatments on increasing the likelihood of adherence to treatment is investigated.

There were some limitations in this research. It was not possible to study the effects of treatment over long run.
Also, this study does not investigate the mechanism of the MBSR intervention effect. Another limitation was the use of a small population in the present study. The intervention was not measured in comparison with the active control group. In addition, in this study, sampling was performed only in one healthcare center, which reduces the generalizability of the results. In conclusion, we suggest that this protocol is followed up in future studies. Also, further research should examine the mechanism of the effects of this intervention. Considering the necessity of increasing the sample size in order to reduce the false positive findings, ${ }^{95}$ it is suggested that future studies repeat the study with a larger sample size. Also, sampling from several health centers can be useful in increasing the generalizability of the results. Finally, we suggest that the study is compared with an active control group.39

\section{List of acronyms}

DASS-21 - Depression, Anxiety, Stress Scale - Short Form

MIDAS - Migraine Disability Assessment Scale

MPQ-SF - McGill's Short Form Questionnaire

MAAS - Mindfulness Inventory

MBSR - Mindfulness-based stress reduction

MBSR-IBB - MBSR in Internet-based bibliotherapy

MTAU - Medical Treatment as Usual

\section{Author's contributions}

All authors contributed equally.

\section{Acknowledgments}

All staff of the Baqiyatallah Hospital and the Headache Clinic, and patients who collaborated are acknowledged and thanked. Funding: None.

\section{Conflict of Interest}

The authors report no conflicts of interests.

\section{Ethical Publication Statement}

We confirm that we have read the Journal's position on issues involved in ethical publication and affirm that this report is consistent with those guidelines.

\section{Corresponding Author}

Yaser Rezapour-Mirsaleh, Counseling Department, Education \& Psychology Faculty, Ardakan University, Ardakan, Iran, Phone: +98 9132548660

Email: y.rezapour@ardakan.ac.ir

E-mails of co-authors

VahidTavallaei: svahidtav@gmail.com

Peyman Rezaiemaram; rezaiemaram@gmail.com

Seyed Hassan Saadat: saadat350@gmail.com

\section{References}

1. Headache Classification Committee of the International Headache Society (IHS). The 
international classification of headache disorders, (beta version). Cephalalgia 2013;33:629-808.

2. Vos T, Flaxman AD, Naghavi M, et al. Years lived with disability (YLDs) for 1160 sequelae of 289 diseases and injuries 1990-2010: a systematic analysis for the Global Burden of Disease Study 2010. Lancet 2013;380(9859):2163-96.

3. Vos T, Allen C, Arora M, et al. Global, regional, and national incidence, prevalence, and years lived with disability for 310 diseases and injuries, 19902015: a systematic analysis for the Global Burden of Disease Study 2015. Lancet 2016;388(10053):1545.

4. Shahbeigi S, Fereshtehnejad SM, Mohammadi N, et al. Epidemiology of headaches in Tehran urban area: a population-based cross-sectional study in district 8, year 2010. Neurol Sci 2013;34:1157-66.

5. Shahrakai MR, Mirshekari H, Ghanbari AT, et al. Prevalence of migraine among medical students in Zahedan Faculty of Medicine (Southeast of Iran). Basic Clin Neurosci 2011;2:20-5.

6. Ayatollahi SMT, Sahebi L, Haghighi AB. Epidemiologic and clinical characteristics of migraine and tension-type headaches among hospitals staffs of Shiraz (Iran). Acta Medica Iranica 2009;47:115-20.

7. Steiner TJ, Birbeck GL, Jensen RH, et al. Headache disorders are third cause of disability worldwide. J Headache Pain 2015;16:1-3.

8. Abu Bakar N, Tanprawate S, Lambru G, et al. Quality of life in primary headache disorders: a review. Cephalalgia 2016;36:67-91.

9. Steiner TJ, Stovner LJ, Vos T. GBD 2015: migraine is the third cause of disability in under $50 \mathrm{~s}$. J Headache Pain 2016;17:104.

10. Salomon JA, Vos T, Hogan DR, et al. Common values in assessing health outcomes from disease and injury: disability weights measurement study for the Global Burden of Disease Study 2010. Lancet. 2013;380(9859):2129-43.

11. Bendtsen L, Jensen R. Tension-type headache: the most common, but also the most neglected, headache disorder. Curr Opin Neurol 2006;19:3059.

12. Jensen R, Stovner LJ. Epidemiology and comorbidity of headache. Lancet Neurol 2008;7:354-61.

13. Silberstein SD, Consortium UH. Practice parameter: Evidence-based guidelines for migraine headache (an evidence-based review) Report of the Quality Standards Subcommittee of the American Academy of Neurology. Neurology 2000;55:75462.

14. Waldie KE, Buckley J, Bull PN, Poulton R. Tension-type headache: A life-course review. Headache 2015;1:1-9.

15. Nash JM, Thebarge RW. Understanding psychological stress, its biological processes, and impact on primary headache. Headache 2006;46:1377-86.

16. Shyti R, de Vries B, van den Maagdenberg A. Migraine genes and the relation to gender. Headache 2011;51:880-90.

17. Nicholson RA, Houle TT, Rhudy JL, et al. Psychological risk factors in headache. Headache. 2007;47:413-26.

18. Kelman L. The triggers or precipitants of the acute migraine attack. Cephalalgia 2007;27:394-402.

19. Sauro KM, Becker WJ. The stress and migraine interaction. Headache 2009;49:1378-86.

20. Turner DP, Houle TT. Psychological evaluation of a primary headache patient. Pain 2013;3:19-25.

21. Smitherman TA, Ward TN. Psychosocial factors of relevance to sex and gender studies in headache. Headache 2011;51(6):923-31.

22. Eskin M, Akyol A, Çelik EY, et al. Social problemsolving, perceived stress, depression and lifesatisfaction in patients suffering from tension type and migraine headaches. Scand $J$ Psychol 2013;54:337-43.

23. Cathcart S, Winefield AH, Lushington $\mathrm{K}$, et al. Stress and tension-type headache mechanisms. Cephalalgia 2010;30:1250-67.

24. Chen S-P, Ayata C. Spreading depression in primary and secondary headache disorders. Current Pain and Headache Reports 2016;20:44.

25. Minen MT, De Dhaem OB, Van Diest AK, et al. Migraine and its psychiatric comorbidities. J Neurol Neurosurg Psych 2016;87:741-49.

26. Sharma M, Upadhyay A, Sharma V. Mental Health Intervention of Migraine Patients by Psychotherapy. The International Journal of Indian Psychology 2017;4:36.

27. Barke A, Gaßmann J, Kröner-Herwig B. Cognitive processing styles of children and adolescents with headache and back pain: a longitudinal epidemiological study. Journal of Pain Research 2014;7:405-14.

28. Demjen S, Bakal DA, Dunn BE. Cognitive correlates of headache intensity and duration. Headache 1990;30:423-7.

29. Tavallaii A, Naderi Z, Rezaiemaram P, et al. The relationship between early maladaptive schemas and three dimensions of headache impact in Iranian outpatients with chronic migraine without aura. International Journal of Behavioral Sciences 2015;9:201-9.

30. Cao M, Zhang S, Wang K, et al. Personality traits in migraine and tension-type headaches: a fivefactor model study. Psychopathology. 2002;35(4):254-8.

31. Taziki S, Saghafi S, Fathi D, et al. Personality characteristics in migraine and tension type headache. J Psychiatry 2014;17:9-14.

32. Rezaei Dogaheh E, Yoosefi A, Kami M. Comparison of maladaptive coping styles in 
patients with migraine and tension headaches with normal group. Practice in Clinical Psychology 2014;2:211-9.

33. Martin PR, Aiello R, Gilson K, et al. Cognitive behavior therapy for comorbid migraine and/or tension-type headache and major depressive disorder: an exploratory randomized controlled trial. Behav Res Ther 2015;73:8-18.

34. Martin PR, MacLeod C. Behavioral management of headache triggers: Avoidance of triggers is an inadequate strategy. Clin Psychol Rev 2009;29:483-95.

35. Sierpina V, Astin J, Giordano J. Mind-body therapies for headache. Am Fam Physician 2007;76:1518-22.

36. Lake AE. Headache and Behavioral Medicine: A 50-Year Retrospective. Headache 2008;48714-8.

37. Sullivan A, Cousins S, Ridsdale L. Psychological interventions for migraine: a systematic review. J Neurol 2016;263:2369-77.

38. Vowles KE, Wetherell JL, Sorrell JT. Targeting acceptance, mindfulness, and values-based action in chronic pain: findings of two preliminary trials of an outpatient group-based intervention. Cognitive and Behavioral Practice 2009;16:49-58.

39. Williams ACdC, Eccleston C, Morley S. Psychological therapies for the management of chronic pain (excluding headache) in adults. The Cochrane Library 2012.

40. Eccleston C, Williams AdC, Morley S. Psychological therapies for the management of chronic pain (excluding headache) in adults. Cochrane Database Syst Rev 2009;2.

41. Ferguson LL. The Role of Acceptance and Pain Intensity in Chronic Pain Disability and Physical Functioning. 2008.

42. Mo'tamedi H, Rezaiemaram P, Tavallaie A. The effectiveness of a group-based acceptance and commitment additive therapy on rehabilitation of female outpatients with chronic headache: preliminary findings reducing 3 dimensions of headache impact. Headache 2012;52:1106-19.

43. Vowles KE, Thompson M. Acceptance and commitment therapy for chronic pain. Mindfulness and acceptance in behavioral medicine: Current theory and practice 2011:31-60.

44. Grossman P, Niemann L, Schmidt S, et al. Mindfulness-based stress reduction and health benefits: A meta-analysis. J Psychosoma Res 2004;57:35-43.

45. Abbott RA, Whear R, Rodgers LR, et al. Effectiveness of mindfulness-based stress reduction and mindfulness based cognitive therapy in vascular disease: A systematic review and metaanalysis of randomised controlled trials. J Psychosom Res 2014;76:341-51.

46. Fjorback L, Arendt M, Ørnbøl E, et al. Mindfulness-based stress reduction and mindfulness-based cognitive therapy: A systematic review of randomized controlled trials. Acta Psychiatr Scand 2011;124:102-19.

47. Omidi A, Zargar F. Effect of mindfulness-based stress reduction on pain severity and mindful awareness in patients with tension headache: A randomized controlled clinical trial. Nursing and Midwifery Studies 2014;3 e21136.

48. Wells RE, Burch R, Paulsen RH, et al. Meditation for migraines: A pilot randomized controlled trial. Headache 2014;54:1484-95.

49. Chang VY, Palesh O, Caldwell R, et al. The effects of a mindfulness-based stress reduction program on stress, mindfulness self-efficacy, and positive states of mind. Stress and Health 2004;20:141-7.

50. Proulx K. Integrating mindfulness-based stress reduction. Holist Nurs Pract 2003;17:201-8.

51. Bakhshani NM, Amirani A, Amirifard H, et al. The effectiveness of mindfulness-based stress reduction on perceived pain intensity and quality of life in patients with chronic headache. Global Journal of Health Science 2016;8:142.

52. Wells RE, Smitherman TA, Seng EK, et al. Behavioral and mind/body interventions in headache: Unanswered questions and future research directions. Headache 2014;54:1107-13.

53. Houghton VT. A quantitative study of the effectiveness of mindfulness-based stress reduction treatment, using an Internet-delivered self-help program, for women with generalized anxiety disorder: Capella University; 2008.

54. Sharma V, Sood A, Prasad K, et al. Bibliotherapy to decrease stress and anxiety and increase resilience and mindfulness: a pilot trial. Explore (NY) 2014;10:248-52.

55. Naylor EV, Antonuccio DO, Litt $M$, et al. Bibliotherapy as a treatment for depression in primary care. J Clin Psychol Med Settings 2010;17:258-71.

56. Fanner D, Urquhart C. Bibliotherapy for mental health service users Part 1: A systematic review. Health Info J 2008;25:237-52.

57. Marrs RW. A meta-analysis of bibliotherapy studies. Am J Community Psychol 1995;23:843-70.

58. Kramer K. Using self-help bibliotherapy in counselling: Lethbridge Alta: University of Lethbridge, Faculty of Education, 2009.

59. Rosenzweig S, Greeson JM, Reibel DK, et al. Mindfulness-based stress reduction for chronic pain conditions: Variation in treatment outcomes and role of home meditation practice. J Psychosom Res 2010;68:29-36.

60. Johnston M, Foster M, Shennan J, et al. The effectiveness of an acceptance and commitment therapy self-help intervention for chronic pain. The Clinical Journal of Pain. 2010;26(5):393-402. 
61. Shechtman Z. The contribution of bibliotherapy to the counseling of aggressive boys. Psychotherapy Research 2006;16:645-51.

62. Cuijpers P, Donker T, Johansson R, et al. Selfguided psychological treatment for depressive symptoms: A meta-analysis. PloS one 2011;6:e21274.

63. Davidson RJ, Kabat-Zinn J, Schumacher J, et al. Alterations in brain and immune function produced by mindfulness meditation. Psychosom Med 2003;65(4):564-70.

64. Fletcher LB, Schoendorff B, Hayes SC. Searching for mindfulness in the brain: A process-oriented approach to examining the neural correlates of mindfulness. Mindfulness 2010;1:41-63.

65. Goldstein E, Stahl B. MBSR Every Day: Daily Practices from the Heart of Mindfulness-Based Stress Reduction: New Harbinger Publications; 2015.

66. Lazar SW, Kerr CE, Wasserman RH, et al. Meditation experience is associated with increased cortical thickness. Neuroreport 2005;16:1893.

67. Siegel RD. The mindfulness solution: Everyday practices for everyday problems: Guilford Press; 2009.

68. Stahl B, Goldstein E. A mindfulness-based stress reduction workbook: New Harbinger Publications; 2010.

69. Kabat-Zinn J. An outpatient program in behavioral medicine for chronic pain patients based on the practice of mindfulness meditation: Theoretical considerations and preliminary results. Gen Hosp Psychiatry 1982;4:33-47.

70. Stewart WF, Lipton RB, Dowson AJ, et al. Development and testing of the migraine disability assessment (MIDAS) questionnaire to assess headache-related disability. Neurology 2001;56:208.

71. Melzack R, Katz J. The McGill Pain Questionnaire: appraisal and current status: Guilford Press; 2001.

72. Melzack R. The short-form McGill pain questionnaire. Pain 1987;30:191-7.

73. Sahebi A, Asghari MJ, Salari RS. Validation of depression anxiety and stress scale (DASS-21) for an Iranian population. Iranian Psychologists 2005;4:299-313.

74. Brown KW, Ryan RM. The benefits of being present: mindfulness and its role in psychological well-being. J Pers Soc Psychol 2003;84:822.

75. Ghorbani N, Watson P, Weathington BL. Mindfulness in Iran and the United States: Crosscultural structural complexity and parallel relationships with psychological adjustment. Current Psychology 2009;28:211.

76. Vowles KE, McCracken LM. Acceptance and values-based action in chronic pain: a study of treatment effectiveness and process. J Consult Clin Psychol 2008;76:397-407.
77. Wong SY-S, Chan FW-K, Wong RL-P, et al. Comparing the effectiveness of mindfulness-based stress reduction and multidisciplinary intervention programs for chronic pain: a randomized comparative trial. The Clinical journal of pain 2011;27:724-34.

78. Morone NE, Lynch CS, Greco CM, et al. "I felt like a new person." The effects of mindfulness meditation on older adults with chronic pain: Qualitative narrative analysis of diary entries. J Pain 2008;9:841-8.

79. Shapiro SL, Carlson LE, Astin JA, et al. Mechanisms of mindfulness. J clin Psychol 2006;62:373-86.

80. Reiner K, Tibi L, Lipsitz JD. Do mindfulness-based interventions reduce pain intensity? A critical review of the literature. Pain Med 2013;14:230-42.

81. Plews-Ogan M, Owens JE, Goodman M, et al. BRIEF report: A pilot study evaluating mindfulness-based stress reduction and massage for the management of chronic pain. J Gen Intern Med 2005;20:1136-8.

82. Harris R. Embracing your demons: An overview of acceptance and commitment therapy. Psychotherapy in Australia. 2006;12:70.

83. McCracken LM, Vowles KE. Acceptance and commitment therapy and mindfulness for chronic pain: Model, process, and progress. American Psychologist 2014;69:178.

84. Kabat-Zinn J, Hanh TN. Full catastrophe living: Using the wisdom of your body and mind to face stress, pain, and illness: Delta; 2009.

85. Charura D, Paul S. The Therapeutic Relationship Handbook: Theory \& Practice: McGraw-Hill Education (UK) 2014.

86. Wilson KG. Mindfulness for two: An acceptance and commitment therapy approach to mindfulness in psychotherapy: New Harbinger Publications; 2009.

87. Segal ZV. Mindfulness and the therapeutic relationship: Guilford Press; 2010.

88. Gilbert P, Leahy RL. The therapeutic relationship in the cognitive behavioral psychotherapies: Routledge; 2007.

89. Carlbring P, Furmark T, Steczkó J, et al. An open study of Internet-based bibliotherapy with minimal therapist contact via email for social phobia. Clinical Psychologist 2006;10:30-8.

90. Muto T, Hayes SC, Jeffcoat T. The effectiveness of acceptance and commitment therapy bibliotherapy for enhancing the psychological health of Japanese college students living abroad. Behav Ther 2011;42:323-35.

91. Mohr DC, Siddique J, Ho J, et al. Interest in behavioral and psychological treatments delivered face-to-face, by telephone, and by internet. Ann Behav Med 2010;40:89-98. 


\section{Chronic Primary Headaches}

Eur J Transl Myol 28 (2): 175-184, 2018

92. Herman PM, Anderson ML, Sherman KJ, et al. Cost-effectiveness of mindfulness-based stress reduction versus cognitive behavioral therapy or usual care among adults with chronic low back pain. Spine 2017;42:1511-20.

93. Andersson G, Lundström P, Ström L. Internetbased treatment of headache: does telephone contact add anything? Headache 2003;43:353-61.
94. Melville KM, Casey LM, Kavanagh DJ. Dropout from Internet-based treatment for psychological disorders. Brit J Clin Psychol 2010;49:455-71.

95. Benjamin DJ, Berger JO, Johannesson $\mathrm{M}$, et al. Redefine statistical significance. Nature Human Behaviour 2018;2:6.

Submission: 25/02/18

Acceptance: $29 / 03 / 18$ 